\title{
The Factors of Smart Factory Construction - Empirical Evidence from Korean Metal Working Firms
}

\author{
Shan Yue Jin ${ }^{1}$ and Ji Suk Lee ${ }^{2}$ \\ ${ }^{1}$ Gachon University, Korea \\ ${ }^{2}$ Korea Institute of Industrial Technology, Korea \\ ${ }^{1}$ jsyrena0923@gachon.ac.kr, ${ }^{2}$ jslee82@kitech.re.kr
}

\begin{abstract}
The Smart Factory is being proposed as a challenge for the manufacturing industry in the 4th Industrial revolution. In the absence of empirical analysis of the status of smart factories, we try to analyze the factors of building a smart factory in the metalworking industry, which is the base of the manufacturing industry. As a result, the CEOs' intentions and firm size are the main factors for innovative and leading investment activities such as smart factories. Also, we find that the level of the smart factory is different according to the industrial characteristics as analyzing the factors of smart level into five working areas (Product Process Design, Operation Management, Quality Management, Equipment Management, and Procurement \& Logistics). In analyzing factors of smart factory construction plan, the firm with high production manpower makes a plan on the low level of the smart plant. It shows that the negative aspects of smart factory construction are strong at the production site.
\end{abstract}

Keywords: 4th industry, CEO, Metalworking firms, Smart factory, SME

\section{Introduction}

The recent controversy over the 4th industrial revolution has created a wave of innovation in the manufacturing industry. The discussion is being concluded at the smart factory in the manufacturing industry as we pursue connectivity, intelligence, and autonomy based on the technologies such as IoT, AI, Cloud, and Big Data. In advanced countries such as Germany, the U.S., and Japan, global companies are leading to make the manufacturing process smart. On the other hand, the organization to support the small and medium-sized enterprises' factories to be smart has been launched by the government in Korea [8]. The cost and manpower problems are still causing the small and medium-sized enterprises to underinvest in 1 smart plants [4] although the need for smart factories is growing.

Nevertheless, some Korean enterprises are early to recognize the change and take the lead in coping with it. In this paper, we try to analyze empirically which companies are investing in smart factories and pursuing innovation using the data on Korean metalworking firms. While the concept definition of smart factories has not been concluded, this paper is the first paper in Korea to explore the direction of smart factory construction according to the characteristics of companies.

Article history:

Received (May 4, 2018), Review Result (July 2, 2018), Accepted (August 24, 2018) 


\section{Preliminary research and hypotheses}

A few kinds of research have been done on smart factories. While contributions and announcements to the smart factory are actively being discussed, particularly we find very little researches in the field of business management. Merely studies on relevant trends in production manufacturing technologies are gradually coming up.

So, in this study, we try to find out the main factors that influence the construction of smart factories that are considered innovations in the manufacturing industry. Above all, the CEO's intention is expected to have the greatest impact on corporate innovation [2], and also firm size, growth on sales, level of research, and investment may be the factors on the establishment of a smart factory because smart factory construction requires a lot of money and connection with information and communication technology. [3] also suggests that the companies with sales of more than 1 trillion won, the ability to invest more than 10 billion won, and executives and employees' enthusiasm for innovation can go to smart factories.

Also, the smart process depends on the characteristics of the industry according to [3] and [6], so we expect that there will be different levels of the smart factory for each industry. In addition, we investigate the main factors that affect the plan of constructing a smart factory in this paper. The level of the planned smart factory is also expected to vary depending on the CEO's intention, the size of the company, and the industry. In particular, it is expected that enterprises that have a large proportion of production manpower that can be replaced by smart equipment will want higher levels of smart factories. The hypotheses to verify these are as follows.

H1: The CEO's intention has a positive impact on the (planning) level of smart factories.

$\mathrm{H} 2$ : Firm size has a positive impact on the (planning) level of smart factories.

H3: Firm growth has a positive impact on the level of smart factories.

H4: R\&D activity has a positive impact on the (planning) level of smart factories.

H5: The (planning) level of smart factories varies depending on the industry.

H6: The proportion of production manpower has a positive impact on the planning level of smart factories.

\section{Research methods and results}

\subsection{Research methods}

In this paper, we analyze the survey data on the 2015 Smart factory Level that was examined for the metalworking firms (Casting, Molding, Forming, Welding, Surface Treatment, and Heat Treatment). Question on the smart level is made on a 5-point scale and the smart level status was investigated by dividing the manufacturing process into five categories (Product Process Design, Operation Management, Quality Management, Equipment Management, and Procurement \& Logistics). Smart levels in each category are not significantly different, but on average, they are estimated at $1.5 \sim 1.8$ points, which are between contracting no smart device and collecting data (saving the data manually). Out of the five working areas, Product Process Design and Operations Management were slightly higher than the others.

Key explanatory variables such as the CEO's intention, industry, and proportion of production manpower are also the results of surveys such as smart level, and we use the KED 
database, which is Korea's largest corporate information database of about 8 million, to define the financial and ownership variable. The variables are described in [Table 1].

Table 1. Definition of variables

\begin{tabular}{|c|c|c|}
\hline Variable & Definition & Formula \\
\hline \multirow{5}{*}{$\begin{array}{l}\text { Smart factory Level } \\
\text { (Current, Plan) }\end{array}$} & (1) Product Process Design & \multirow{5}{*}{5 point scale } \\
\hline & (2) Operation Management & \\
\hline & (3) Quality Management & \\
\hline & (4) Equipment Management & \\
\hline & (5) Procurement \& Logistics & \\
\hline CEO's Intention & CEO's commitment to building a smart factory & 5 point scale \\
\hline Firm size & Size of Enterprise & $\ln$ (Total Asset) \\
\hline Growth & Recent sales growth & $\begin{array}{l}\text { The past three-year average } \\
\text { sales growth }\end{array}$ \\
\hline $\mathrm{R} \& \mathrm{D}$ & R\&D Ratio & R\&D expense/ Total Sales \\
\hline Industry Dummy & $\begin{array}{l}\text { Casting, Molding, Forming, Welding, Surface } \\
\text { Treatment, Heat Treatment }\end{array}$ & Dummy Variables \\
\hline Debt Ratio & Soundness of Enterprise & Total Debt/Total Asset \\
\hline Large shareholder & Largest Shareholder Ownership Ratio & $\begin{array}{l}\text { Largest Shareholder Ownership } \\
\text { Percentage }\end{array}$ \\
\hline Production manpower & Field Workers' Ratio & Field Workers/Total Workers \\
\hline
\end{tabular}

\subsection{Results}

We use 122 corporate data for this study and present the results of multiple regression analyses on the level of the smart factory in [Table 2]. The results show that the CEOs' intentions and firm size have a positive impact on the level of smart factories supporting hypotheses 1 and 2. Also, we find that the level of the smart factory is different according to the industrial characteristics supporting hypothesis 5. In particular, casting firms are analyzed to be higher than other industries in quality management, molding and forming firms are higher in product process design, and surface treatment firms are higher in operation and quality management and procurement \& logistics. However, contrary to our expectations, sales growth and R\&D activity do not have any impact on the smart level.

Table 2. The results of the regression analysis

\begin{tabular}{|c|c|c|c|c|c|}
\hline \multirow{2}{*}{ Variables } & \multicolumn{5}{|c|}{ Dependent Variables: Smart factory Current Level } \\
\cline { 2 - 6 } & $(1$ & $(2)$ & 3 & 4 & -1.090 \\
\hline \multirow{2}{*}{ Constant } & -1.386 & -0.802 & -0.798 & $-1.895^{*}$ \\
& $(-1.50)$ & $(-0.97)$ & $(-1.09)$ & $(-1.45)$ & $(-1.89)$ \\
\hline CEO's & $0.297 * * *$ & $0.221^{* * *}$ & $0.338^{* * *}$ & $0.175^{* * *}$ & $0.314^{* * *}$ \\
intention & $(3.85)$ & $(3.20)$ & $(5.50)$ & $(2.79)$ & $(3.76)$ \\
\hline \multirow{2}{*}{ Firm size } & $0.108^{* *}$ & $0.088^{*}$ & 0.055 & $0.108^{* *}$ & $0.119^{* *}$ \\
& $(2.06)$ & $(1.90)$ & $(1.32)$ & $(2.54)$ & $(2.11)$ \\
\hline \multirow{2}{*}{ Growth } & 0.576 & 0.360 & 0.177 & 0.097 & -0.289 \\
& $(1.60)$ & $(1.12)$ & $(0.62)$ & $(0.33)$ & $(-0.74)$ \\
\hline \multirow{2}{*}{ R\&D } & -1.784 & -3.660 & -1.313 & -1.549 & -1.806 \\
& $(-0.45)$ & $(-1.03)$ & $(-0.42)$ & $(-0.48)$ & $(-0.42)$ \\
\hline \multirow{2}{*}{ Casting } & $0.575^{* *}$ & $0.389 *$ & $0.591 * * *$ & $0.366^{*}$ & 0.184 \\
& $(2.28)$ & $(1.73)$ & $(2.95)$ & $(1.78)$ & $(0.68)$ \\
\hline
\end{tabular}




\begin{tabular}{|c|c|c|c|c|c|}
\hline Molding & $\begin{array}{c}0.691 * * * \\
(2.81)\end{array}$ & $\begin{array}{c}0.245 \\
(1.12)\end{array}$ & $\begin{array}{c}0.191 \\
(0.98)\end{array}$ & $\begin{array}{c}0.104 \\
(0.52)\end{array}$ & $\begin{array}{c}0.119 \\
(0.45)\end{array}$ \\
\hline \multirow{2}{*}{ Forming } & $0.574 * *$ & $0.437 * *$ & $0.384 * *$ & 0.233 & 0.183 \\
& $(2.35)$ & $(2.00)$ & $(1.98)$ & $(1.17)$ & $(0.69)$ \\
\hline \multirow{2}{*}{ Welding } & 0.322 & 0.152 & 0.258 & -0.120 & 0.329 \\
& $(1.18)$ & $(0.63)$ & $(1.19)$ & $(-0.54)$ & $(1.12)$ \\
\hline Surface & $0.464 *$ & $0.612^{* * *}$ & $0.633^{* * *}$ & $0.375^{*}$ & $0.537 *$ \\
Treatment & $(1.93)$ & $(2.85)$ & $(3.31)$ & $(1.91)$ & $(2.06)$ \\
\hline \multirow{2}{*}{ Debt Ratio } & -0.176 & -0.170 & -0.137 & -0.073 & 0.045 \\
& $(-0.61)$ & $(-0.66)$ & $(-0.60)$ & $(-0.31)$ & $(0.14)$ \\
\hline Large & -0.179 & -0.050 & -0.051 & 0.117 & 0.026 \\
shareholder & $(-0.79)$ & $(-0.25)$ & $(-0.04)$ & $(0.63)$ & $(0.10)$ \\
\hline No. of Obs. & 122 & 122 & 122 & 122 & 122 \\
\hline Adj. R2 & 0.27 & 0.21 & 0.31 & 0.18 & 0.17 \\
\hline F value & 5.12 & 3.99 & 5.83 & 3.49 & 3.18 \\
\hline
\end{tabular}

In analyzing factors of the smart factory construction plan, the CEO's intention has the greatest impact just like the result of analysis on the current smart level. Firm size is also analyzed as the main factor to affect planning level of smart factory although the impact is weaker than on current smart level. Especially, among metalworking firms, casting, molding, and forming firms are analyzed to plan to build higher-level smart factories.

On the other hand, it is analyzed that the companies with high production manpower make a plan on the low level of the smart plant. The result could be interpreted that the companies with more production staff have difficulties in promoting smart plants [6]. It shows that the negative aspects of smart factory construction are strong at the production site.

\section{Conclusion}

While there is no doubt that smart factory construction is the way to prepare for the 4th industry in the manufacturing industry, it is not discussed to what extent it should be preceded according to the corporate characteristics. Since smart factory construction requires a lot of money and effort, the plans on smart factories need to be considered by the industry for successful investment. So, in this study, we analyze the impact of corporate characteristics on the level of smart factories in the manufacturing sector especially the metalworking industry.

As a result, the CEO's willpower and firm size are the main factors to determine innovative and leading investment activities, such as smart factories. In addition, we confirm that the smart level of the manufacturing process is different depending on the industry characteristics.

Meanwhile, the regression result of companies with high production manpower making a plan on the low level of smart factory suggests that it should not be overlooked that smart factory is not simply built and completed with smart systems, but can evolve through collaboration on the production site.

\section{References}

[1] C. Schroder, "The challenges of industry 4.0 for small and medium-sized enterprises," (2016)

[2] D. C. Hambrick and P. A. Mason, "The Academy of Management Review," vol.9, no.2, pp.193-206

[3] H. G. Park, "Smart factory strategy conference," July 3: Seoul, Korea, (2018)

[4] H. J. Lee, Y. J. Kim, J. J. Yim, Y. W. Kim, and S. H. Lee, "Journal of the Korean Society for Precision Engineering," vol.34, no.1, pp.29-34, (2017)

[5] H. Y. Park, "The journal of the Korean institute of communication sciences," vol.33, no.1, pp.24-29, (2015)

[6] H. Y. Lee and J. Y. Chang, "The journal of the Korean institute of communication sciences," vol.35, no.4, pp.35-42, (2018) 
[7] T. G. Kang and Y. R. Kim, "Indian journal of science and technology," vol.9 (S1), (2016)

[8] T. J. Lee and Y. J. Kim, "Proceedings of the Korean society of computer information conference," (2017), vol.25. no.2, pp.191-194

[9] KPIC, "Survey report on smart factory level of metalworking firms, (2015) 


\section{Authors}

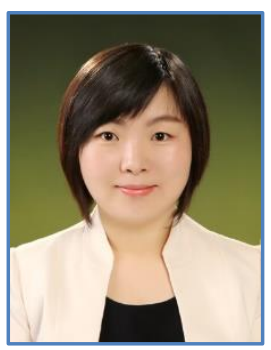

Shan Yue Jin

Gachon University

Assistant Professor

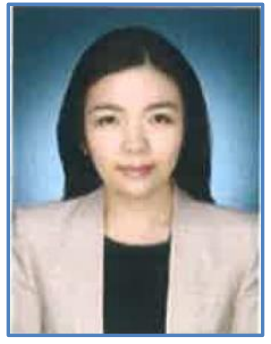

Ji Suk Lee

Korea Institute of Industrial Technology

Researcher 